\title{
Oceanography
}

CITATION

Paola, C. 2011. Review of River Discharge to the Coastal Ocean: A Global Synthesis, by

J.D. Milliman and K.L. Farnsworth. Oceanography 24(4):143-144, http://dx.doi.org/10.5670/

oceanog.2011.108.

DOI

http://dx.doi.org/10.5670/oceanog.2011.108

COPYRIGHT

This article has been published in Oceanography, Volume 24, Number 4, a quarterly journal of The Oceanography Society. Copyright 2011 by The Oceanography Society. All rights reserved.

USAGE

Permission is granted to copy this article for use in teaching and research. Republication, systematic reproduction, or collective redistribution of any portion of this article by photocopy machine, reposting, or other means is permitted only with the approval of The Oceanography Society. Send all correspondence to: info@tos.org or The Oceanography Society, PO Box 1931, Rockville, MD 20849-1931, USA. 


\section{River Discharge to the Coastal Ocean: A Global Synthesis}

By John D. Milliman and Katherine L. Farnsworth, Cambridge University Press, 2011, 392 pages, ISBN 978-0-521-87987-3, Hardcover, \$160 US

\section{REVIEWED BY CHRIS PAOLA}

There was a time when "blue water" oceanographers didn't think much about the coastal oceans, let alone the arterial strands of freshwater that supply them with sediment, solutes, organisms, and a variety of other cargo. Fortunately, this phase is behind us, and the publication of this interesting new book by Milliman and Farnsworth on river discharge to the ocean nicely reflects its passing. This book is about rivers, but is written for oceanographers. It focuses not on how rivers work but on what they deliver to the ocean. It provides 164 pages of analysis of how we measure the mass fluxes that rivers deliver to the world ocean, the temporal and spatial variability of delivery rates around the world, and what factors might account for the variation. It is unusual among books today in that it is nearly exclusively devoted to data. The authors take data quality very seriously, which is good, especially in a work that synthesizes data from sources around the world that differ widely in quality. For rivers in wealthy countries, we have long records of consistent quality. For most of the world's rivers, the data are much more spotty. This variability is a major obstacle in compiling a global database for riverborne fluxes, which for the most part must still be measured on the ground and by human operators. Although some of the data presented in this book are already available online, I don't know of anything as comprehensive as this book, or that provides the level of synthesis and quality control found here.

Rivers discharge many things to the coastal ocean; the main quantities of interest here are water, sediment (mainly as suspended sediment), and total dissolved load. Water gets its share of attention, but there are many other sources of information about water; the emphasis on sediment and solutes is the distinctive feature of this book. The first author (Milliman) has published extensively on the disproportionate share of global sediment delivery associated with short, steep streams in tectonically active settings, and the book develops this important idea further. There is a good deal of careful analysis of the relative influence of climate, relief, and lithology on both suspended sediment and solute production. Dissolved load is not broken down into constituents beyond silica, so those readers interested in nutrient fluxes will have to supplement this book with additional information. As the authors point out, data on nutrient and carbon fluxes are readily available elsewhere, though it would be nice in a future edition to include at least the major solutes in the book's appealing format.

The main text concludes with major chapters on temporal variations and human effects. The former looks at the influences on river discharge to the ocean of the growing array of recognized
River Discharge to

the Coastal Ocean A GLOBAL sYNTHEsis Row

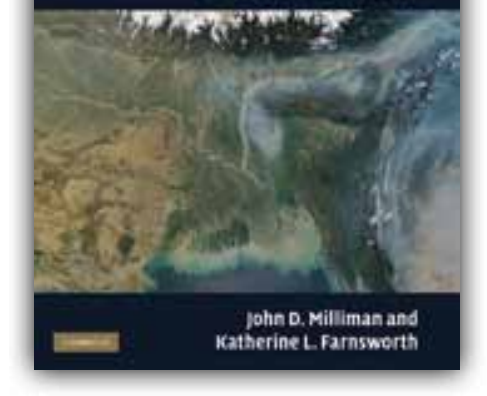

climate cycles, on various timescales. This discussion is complemented by a careful look at the influence of individual events, chiefly storms and earthquakes, that dramatically, though temporarily, increase material transfer. The strong human imprint that is becoming the new norm for thinking in the environmental sciences is well illustrated in the lengthy final chapter of the main text. I particularly appreciate the authors' point that, although climate change clearly could have strong direct and indirect effects on river systems, they are unlikely to match the already large effects of land use and other less well-publicized human actions on rivers and the loads they deliver to the ocean. Another point, made repeatedly in the literature and emphasized here, is that on a global scale, humans have increased rates of particulate and dissolved transfer to rivers, but paradoxically, the delivery rate of particulates to the coastlines has diminished. The cause is damming, and the net effect is a mass transfer from interior uplands to the midsections of the world river system.

Reading a data compilation sounds about as exciting as painting with neutral colors or eating bran flakes, but this book is actually quite engaging. The writing style is clear, direct, and 
informal, and the authors have worked hard to bring out the meaning of the data they've assembled, frequently using boxed and inline case studies from around the world to illustrate the major points. They take the "global" in the title seriously-the examples are nicely balanced around the world. Beyond that, Milliman and Farnsworth do a nice job of conveying, by example, their passion for data-the vagaries of collecting and quality checking data, how to coax insight from them, and the stories they tell about how Earth's surface works and how it is changing. In an era when data collection increasingly refers to various forms of remote sensing, it is worth reflecting on the fact that a lot of the data in this book are collected, or at least cross-checked, by hand. River discharge remains one of the semi-artisanal corners of the Earth sciences.

Like all high-quality printed books these days, this one is not cheap. By current standards, the price is reasonable for what it provides: an abundance of useful, quality-controlled data; thoughtful analysis and synthesis; and nicely produced figures, mostly in color. Much of the data is available online in various places, but even a quick read of the introductory discussion of sources and quality control makes clear the value the authors have added by putting the data together as they have. In this regard, a nice bonus is that the whole data set can be accessed in tabulated form electronically via the Cambridge University

Press website. Anyone interested in continental- to global-scale particle and dissolved fluxes from the continents to the world ocean will benefit from having this material close at hand-if not on a nearby shelf, then at least in the library. The book also provides the raw material for any number of useful teaching exercises in Earth system science, where land-ocean mass fluxes are critical.

Chris Paola (cpaola@umn.edu) is Professor of Geology and Geophysics and College of Science and Engineering Distinguished Professor, Department of Earth Sciences, St. Anthony Falls Laboratory, University of Minnesota, Minneapolis, MN, USA.

\section{Sex, Drugs, and Sea Slime:} The Oceans' Oddest Creatures and Why They Matter

\section{By Ellen Prager, University of Chicago}

Press, 2011, 200 pages, ISBN 978-0-226-

67872-6, Softcover and E-book, \$12 US

\section{REVIEWED BY JEFFREY C. DRAZEN}

Ellen Prager's book presents an entertaining account of the lives of many marine organisms. Its stories are understandable, fun to read, and focus on describing the curious attributes and mysterious lives ocean creatures lead. As the title indicates, the stories often concern reproduction, drug development, or the use of slime, but these threads in no way constrained the storytelling. Even though the preface includes the disclaimer that the book is not a comprehensive text, the coverage is impressive. It begins, quite logically, with a chapter on plankton, aptly named "The Invisible Crowd." Ten chapters follow, including introductions to life on a coral reef, the various predation strategies of marine organisms, and, in a chapter entitled "X-Games," some of the amazing ecological and physiological adaptations that marine animals have evolved for high performance and survival in the ocean. I was impressed with the diversity of life covered. Prager does not focus solely on glamorous marine mammals and fishes, although her stories about these animals are very interesting. There is an entire chapter on snails, a story about the amazing growth potential of kelp, a description of deep-sea boneeating polychaete worms, and discussion

\section{ELLEN PRAGER}

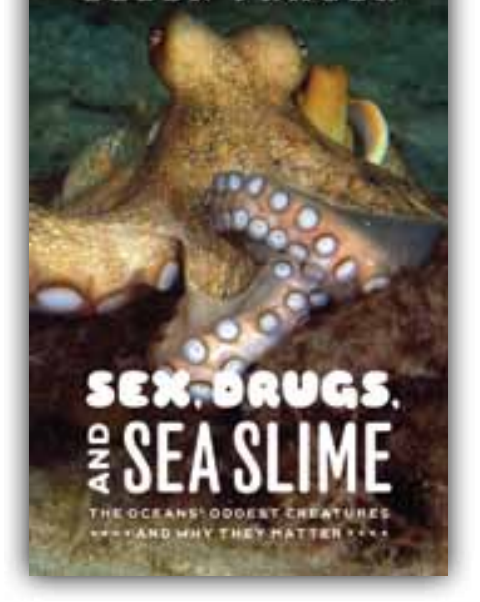

about microbes at hydrothermal vents, just to name a few of the less-conventional organisms covered.

The book is written for the layperson who has an interest in ocean life. Prager's storytelling is funny and filled with interesting facts that are sure to instill amazement and stimulate curiosity. There are tales of lobsters shooting streams of pee 